\title{
Morphological alterations induced by doxorubicin on H9c2 myoblasts: nuclear, mitochondrial, and cytoskeletal targets
}

\author{
Vilma A. Sardão • Paulo J. Oliveira • Jon Holy • \\ Catarina R. Oliveira $\cdot$ Kendall B. Wallace
}

Received: 18 December 2007 / Accepted: 28 February 2008

(C) Springer Science + Business Media B.V. 2008

\begin{abstract}
Doxorubicin (Dox) is a very potent antineoplastic agent used against several types of cancer, despite a cumulative cardiomyopathy that reduces the therapeutic index for treatment. H9c2 myoblast cells have been used as an in vitro model to study biochemical alterations induced by Dox treatment on cardiomyocyte cells. Despite the extensive work already published, few data are available regarding morphological alterations of $\mathrm{H} 9 \mathrm{c} 2$ cells during Dox treatment. The purpose of the present work was to evaluate Doxinduced morphological alterations in $\mathrm{H} 9 \mathrm{c} 2$ myoblasts, focusing especially on the nuclei, mitochondria, and structural fibrous proteins. Treatment of H9c2 cell with
\end{abstract}

V. A. Sardão $(\bowtie) \cdot$ P. J. Oliveira

Center for Neurosciences and Cellular Biology,

Department of Zoology, University of Coimbra,

3004-517 Coimbra, Portugal

e-mail: vimarisa@ci.uc.pt

J. Holy

Department of Anatomy, Microbiology and Pathology, University of Minnesota Medical School,

Duluth, USA

C. R. Oliveira

Center for Neurosciences and Cellular Biology, Department of Biochemistry, Medical School, University of Coimbra, Coimbra, Portugal

K. B. Wallace

Department of Biochemistry and Molecular Biology,

University of Minnesota Medical School,

Duluth, USA low concentrations of Dox causes alterations in fibrous structural proteins including the nuclear lamina and sarcomeric cardiac myosin, as well as mitochondrial depolarization and fragmentation, membrane blebbing with cell shape changes, and phosphatidylserine externalization. For higher Dox concentrations, more profound alterations are evident, including nuclear swelling with disruption of nuclear membrane structure, mitochondrial swelling, and extensive cytoplasm vacuolization. The results obtained indicate that Dox causes morphological alterations in mitochondrial, nuclear, and fibrous protein structures in $\mathrm{H} 9 \mathrm{c} 2$ cells, which are dependent on the drug concentration. Data obtained with the present study allow for a better characterization of the effects of Dox on H9c2 myoblasts, used as a model to study Dox-induced cardiotoxicity. The results obtained also provide new and previously unknown targets that can contribute to understand the mechanisms involved in the cardiotoxicity of Dox.

Keywords Cytoskeleton - Doxorubicin . $\mathrm{H} 9 \mathrm{c} 2$ myoblasts $\cdot$ Mitochondria $\cdot$ Nuclei
Abbreviations
DIC differential interference contrast
Dox doxorubicin
LDH lactate dehydrogenase
PS phosphatidylserine
ROS reactive oxygen species
TMRM tetramethylrhodamine methyl ester 


\section{Introduction}

Doxorubicin (Dox) is one of the most potent antineoplastic drugs prescribed alone or in combination with other agents in the treatment of various types of tumors. The antineoplastic mechanism of Dox has been attributed to intercalation of the planar anthracycline ring into the DNA helix (Box 2007) and/or covalent binding to proteins involved in DNA replication and transcription. Such interactions result in inhibition of DNA, RNA, and protein synthesis, leading ultimately to cell death (Cutts et al. 2005; Cutts et al. 1996). However, clinical use of Dox is restrained by a chronic and cumulative cardiotoxicity that is manifested as a dilated congestive heart failure (Takemura and Fujiwara 2007). Impaired body weight gain and irreversible electrocardiogram alterations (prolongation of ST and QT intervals) are observed in rats 5 weeks after Dox administration (Villani et al. 1990). Decrease in left ventricular developed pressure, increase in coronary perfusion pressure, ventricular fibrillation, shortening of ventricular action potential duration, reduction in cardiac index (cardiac output/body weight), and an increase in total peripheral resistance were some other parameters altered in rat and rabbit hearts in conjunction with morphological and biochemical alterations after Dox treatment (Joyeux et al. 2001; Potemski et al. 2006).

Marked dilation of the sarcoplasmic reticulum and mitochondrial damage (Iwasaki and Suzuki 1991) were previously observed in the myocardium after Dox treatment. Contractile performance of atria is significantly reduced, accompanied by myocyte vacuolization and myofibrillar loss (Villani et al. 1990). Endomyocardial biopsies performed in human hearts after Dox administration reveals an increase in sarcoplasmic reticulum and T-tubule size, again accompanied by cytoplasmic vacuolization. Nuclear changes include clumping of chromatin and nucleolar shrinkage, along with segregation of granular and fibrillar components (Unverferth et al. 1981). These alterations were reported to be more marked with increasing dose of drug, but not with longer duration of perfusion (Taylor and Bulkley 1982). Decreases in contraction amplitude, velocity, and oxygen consumption were also observed in cardiac myocytes isolated from hearts of rabbits treated with Dox (Jones et al. 1990). Low myosin content was proposed to be involved in the decreased contractility observed after
Dox treatment contributing to the reduced cardiac output (Jones et al. 1990).

Generation of reactive oxygen species has been proposed to be responsible for the toxicity of Dox (Xu et al. 2001). In mitochondria, Dox is reduced to a reactive semiquinone by complex I, reoxidizing to the original form by univalent reduction of oxygen. The process produces oxidative stress, which initially mostly affects the mitochondria (Xu et al. 2001).

One result of Dox toxicity is apoptosis, which may be responsible for cardiomyocyte death, although the exact mechanism is still being investigated (Kalyanaraman et al. 2002).

Animal models, primary cultures of cardiomyocytes, and transformed cell lines have all been used to investigate the mechanism by which Dox is selectively cardiotoxic. The myoblastic cell line H9c2 (Kimes and Brandt 1976) is a well-characterized in vitro system used to study Dox-induced biochemical changes and the protective effect of a wide number of compounds (Chua et al. 2006; L'Ecuyer et al. 2006; Spallarossa et al. 2004; Wattanapitayakul et al. 2005). For example, a recent study demonstrated that Dox treatment leads to hypertrophy of $\mathrm{H} 9 \mathrm{c} 2$ cells (Merten et al. 2006), similar to what has been observed in adult cardiomyocytes during the development of the Dox-induced cardiomyopathy (Lushnikova et al. 2004). Despite some work conducted on the biochemical alterations of $\mathrm{H} 9 \mathrm{c} 2$ cells induced by Dox, the evaluation and characterization of morphological modifications has not been extensively studied.

The objective of this work was to assess, through microscopy, alterations in cell morphology, which are correlated with the appearance of apoptotic hallmarks upon exposure of H9c2 myoblasts to Dox. With the present study, it was also our intention to focus on alterations in $\mathrm{H} 9 \mathrm{c} 2$ cell morphology resulting from exposure to several concentrations of Dox, which will contribute to the understanding of the unique sensitivity of cardiomyocytes to this anti-neoplastic agent.

\section{Material and methods}

Reagents Dulbecco's modified Eagle's medium (DMEM), penicillin, streptomycin, fetal bovine serum, and trypsin-ethylenediaminetetraacetic acid (EDTA) were purchase from Gibco-Invitrogen (Grand Island, NY, USA). Doxorubicin, dithiothreitol (DTT), 
phenylmethanesulfonyl fluoride (PMSF), and protease inhibitor cocktail (leupeptin, antipain, chymostatin, and pepstatin A) were obtained from Sigma (St Louis, MO, USA). Caspases substrates and $p$-nitroanilide ( $p$-NA) were purchased from Calbiochem (San Diego, CA, USA). Hoechst 33342, tetramethylrhodamine methyl ester (TMRM), calcein-AM, propidium iodide (PI), and $N$-(7)-nitrobenz-2-oxa-1,3-diazol-4-yl (NBD)-phallacidin were obtained from Molecular Probes (Eugene, OR, USA). Annexin V-fluorescein isothiocyanate (FITC) was purchased from BD Bioscience Pharmingen (San Diego, CA, USA). MF20 and CMII23 antibodies were purchased from Developmental Studies Hybridoma Bank, Iowa City, IA, USA. The rabbit polyclonal antibodies to lamins $\mathrm{A} / \mathrm{C}$ and $\mathrm{B} 1$ were a gift from Dr. H. Worman (Columbia University, NY, USA). Secondary antibody FITC-conjugated anti-mouse IgG antibody was purchased from Jackson ImmunoResearch Laboratories, Inc. (Cambridgeshire, UK).

Cell Culture The H9c2 cell line, originally derived from embryonic rat heart tissue using selective serial passages (Kimes and Brandt 1976), was purchased from America Tissue Type Collection (Manassas, VA; catalog no. CRL-1446). Cells were cultured in DMEM supplemented with $1.5 \mathrm{~g} / 1$ sodium bicarbonate, $10 \%$ fetal bovine serum, $100 \mathrm{U} / \mathrm{ml}$ of penicillin, and $100 \mu \mathrm{g} / \mathrm{ml}$ of streptomycin in $75 \mathrm{~cm}^{2}$ tissue culture flasks at $37^{\circ} \mathrm{C}$ in a humidified atmosphere of $5 \% \mathrm{CO}_{2}$. Cells were fed every $2-3$ days and subcultured once they reached $70-80 \%$ confluence. For epifluorescence or confocal microscopy, cells were seeded at a density of 35,000 cells per milliliter in glass-bottom dishes (Mat-Tek Corporation, Ashland, MA, USA). For lactate dehydrogenase (LDH) measurements, H9c2 cells were seeded in 12-well plates culture dishes at a subcultivation ration of 1:4. After seeding, cells were allowed to grow for 3 days to reach the desired confluence ( $>80-90 \%)$. For detection of phosphatidylserine (PS) exposure, chromatin condensation studies and immunocytochemistry assay cells were seeded in six-well plates containing glass coverslips (final volume of $2 \mathrm{ml} /$ well). For electron microscopy and caspase-3- and caspase-9-like activity measurement, cells were seeded in $75 \mathrm{~cm}^{2}$ tissue culture flasks at a subcultivation ratio of 1:5. Cells were then allowed to grow for 4-5 days to reach the desired confluence ( $\backsim 80-90 \%)$. Cells were seeded in
DMEM with $10 \%$ fetal bovine serum, and experiments were carried out up to $24 \mathrm{~h}$ post-treatment. Dox was directly added to the cell culture media at described concentrations.

Cytoskeletal and sarcomeric labeling H9c2 cells, seeded on glass coverslips in six-well plates, were incubated with or without Dox for $24 \mathrm{~h}$ at the indicated concentrations. For F-actin labeling, cells were rinsed with cold phosphate-buffered saline (PBS), fixed with 4\% paraformaldehyde during $15 \mathrm{~min}$ at room temperature, rinsed again with PBS, and stored in PBS Tween-20 (PBST) at $4{ }^{\circ} \mathrm{C}$ until use. For cardiac myosin heavy chain (MF-20 Antibody), myosin IIB heavy chain (CMII23 antibody), and lamins $\mathrm{A} / \mathrm{C}$ and $\mathrm{B} 1$ immunolabeling, cells were fixed and stored at $-20^{\circ} \mathrm{C}$ in ice-cold absolute methanol. Cells fixed with paraformaldehyde were permeabilized with $0.2 \%$ Triton $\mathrm{X}-100$ in PBS for $5 \mathrm{~min}$ at room temperature after three washes with PBS. Cells fixed with ice-cold methanol were rehydrated with PBST during $5 \mathrm{~min}$ for three times. Cells were incubated in blocking solution (PBST supplemented with $1 \%$ non-fat powdered milk) for $30 \mathrm{~min}$ at $37^{\circ} \mathrm{C}$, probed with specific primary antibody (MF-20; CMII23; lamin $\mathrm{A} / \mathrm{C}$, dilution 1:50; and lamin $\mathrm{B} 1$, dilution 1:50) during $2 \mathrm{~h}$ at $37^{\circ} \mathrm{C}$ and stained with FITC- or Texas Red-conjugated secondary antibody (goat anti-rabbit for lamins $\mathrm{A} / \mathrm{C}$ and $\mathrm{B} 1$, dilution 1:50; and goat anti-mouse for MF-20 and CMII23, dilution 1:50), containing $5 \mu \mathrm{g} / \mathrm{ml}$ of Hoechst 33342, for an additional $2 \mathrm{~h}$ at $37^{\circ} \mathrm{C}$. Between labeling with primary and secondary antibodies, cells were rinsed with PBST three times during $5 \mathrm{~min}$ each. For F-actin labeling, NBD-phallacidin was prepared following the manufacturer's instructions and supplemented with sodium azide and Hoechst $33342(0.05 \%$ and $5 \mu \mathrm{g} / \mathrm{ml}$ final concentrations, respectively). The final working solution was applied directly to the coverslips for $2 \mathrm{~h}$ at $37^{\circ} \mathrm{C}$. After labeling, coverslips were mounted on glass slides in an anti-fade medium consisting of nine parts glycerol and one part $0.1 \mathrm{M} \mathrm{N}$-cyclohexyl-3aminopropanesulfonic acid buffer, $\mathrm{pH}$ 9.0, supplemented with $0.1 \%$ phenylenediamine and $0.1 \% 1$, 4-diazabicyclo[2.2.2] octane (both from Sigma Chemical Co.). Cells were observed by epifluorescence microscopy using a Nikon Eclipse TE2000U microscope. The fluorescein filter was used for FITC and NBD-phallicidin imaging and the rhodamine filter for 
Texas Red fluorescence imaging. Images were obtained using Metamorph software (Universal Imaging, Downington, PA, USA).

Triple labeling of $H 9 \mathrm{c} 2$ cells with TMRM, Hoechst 33342, and calcein-AM, and visualization by confocal microscopy H9c2 cells in glass-bottom dishes were incubated with TMRM (100 nM), Hoechst 33342 $(1 \mu \mathrm{g} / \mathrm{ml})$, and calcein-AM $(300 \mathrm{nM})$ for $30 \mathrm{~min}$ at $37^{\circ} \mathrm{C}$ in the dark. Due to the very low fluorescence of the probes in the extracellular media, the images were collected without replacing the cell culture media. The images were obtained using a Nikon C-1 laser scanning confocal microscope. TMRM signal was acquired using a green $\mathrm{He}-\mathrm{Ne}$ laser, the calcein-AM signal was acquired using an air-cooled argon laser, and the Hoechst signal was obtained by using a violet diode laser. Differential interference contrast (DIC) images using the confocal microscope were collected using the air-cooled argon laser and the appropriate detector.

Labeling of mitochondria in H9c2 cells with TMRM and visualization by epifluorescence microscopy $\mathrm{H} 9 \mathrm{c} 2$ cells in glass-bottom dishes were incubated with TMRM $(100 \mathrm{nM})$ for $30 \mathrm{~min}$ at $37^{\circ} \mathrm{C}$ in the dark. Due to the very low fluorescence of the probes in the extracellular media, the images were collected without replacing the cell culture media. Cells were observed by epifluorescence microscopy using a Nikon Eclipse TE2000U microscope.

Analysis of nuclear alterations and cytoplasm vacuolization in $\mathrm{H} 9 \mathrm{c} 2$ cells Alterations in nuclear size and the appearance of cytosolic vacuoles were observed by microscope analysis by using phase contrast $(\times 40$ objective) or differential interference contrast (DIC, $\times 60$ objective). Cells were seeded as described before and treated with Dox for the chosen time points. Image J 1.331 (NIH, USA) was used to measure the size of cell nuclei. At least five random fields of view were examined for each treatment group.

Electron microscopy of $\mathrm{H} 9 \mathrm{c} 2$ cells After treatment, trypsinized $\mathrm{H} 9 \mathrm{c} 2$ cells were fixed for electron microscopy using $3 \%$ glutaraldehyde in $0.1 \mathrm{M}$ sodium

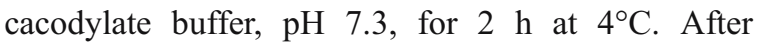
centrifugation (15,000 rpm, $3 \mathrm{~min}$ ), pellets were washed with $0.1 \mathrm{M}$ sodium cacodylate buffer $(\mathrm{pH} 7.3)$. The fixed and washed pellet was resuspended in $1 \% \mathrm{OsO} 4$ buffered with sodium cacodylate $0.1 \mathrm{M}, \mathrm{pH}$ 7.3. After $2 \mathrm{~h}$ incubation, pellets were washed with cacodylate buffer $\mathrm{pH}$ 7.3. Pellets were embedded in 1\% agar, subsequently dehydrated in a graded ethanol, and embedded in Spurr's resin. Ultrathin sections were obtained with a LKB ultra-microtome Ultrotome III and stained with methanolic uranyl acetate followed by lead citrate and examined with a Jeol Jem-100SX electron microscope operated at $80 \mathrm{kV}$.

Annexin V/PI assay Annexin V-FITC was used in conjunction with a vital dye, PI, to distinguish apoptotic (annexin V-FITC-positive, PI-negative) from necrotic/late-apoptotic (annexin V-FITC-positive, PIpositive) cells. After treatment with Dox, culture media was removed, cells were washed twice with ice-cold $1 \times$ PBS and incubated with $100 \mu$ of annexin V incubation reagent (10 mM 4-2-hydroxyethyl-1-piperazineethanesulfonic acid (HEPES), $\mathrm{pH} 7.4,150 \mathrm{mM}$ $\mathrm{NaCl}, 5 \mathrm{mM} \mathrm{KCl}, 1 \mathrm{mM} \mathrm{MgCl} 2,2.5 \mathrm{mM} \mathrm{CaCl}_{2}$ supplemented with $5 \mu \mathrm{g} / \mathrm{ml}$ PI and with annexin VFITC diluted 1:20) during $15 \mathrm{~min}$ at room temperature in the dark. After two washes with $1 \times$ binding buffer (10 mM HEPES, pH 7.4, $150 \mathrm{mM} \mathrm{NaCl}, 5 \mathrm{mM} \mathrm{KCl}$, $1 \mathrm{mM} \mathrm{MgCl}_{2}, 2.5 \mathrm{mM} \mathrm{CaCl}_{2}$ ), cells were observed by fluorescence microscopy using an Nikon Eclipse TE2000U epifluorescence microscope, and images were obtained using Metamorph software (Universal Imaging, Downingtown, PA, USA).

Caspase-like activity assay Total cellular extracts were used for caspase activity assays. After Dox treatment, $\mathrm{H} 9 \mathrm{c} 2$ cells were harvested by trypsinization and washed once with PBS. To collect total cells, two centrifugation steps were performed for $5 \mathrm{~min}$ at $1,000 \times \mathrm{g}$. Floating (dead) cells were also collected and combined with adherent cells. Cellular pellets were resuspended in collecting buffer $(20 \mathrm{mM}$ HEPES/NaOH, pH 7.5, $250 \mathrm{mM}$ sucrose, $10 \mathrm{mM} \mathrm{KCl}, 2 \mathrm{mM} \mathrm{MgCl} 2,1 \mathrm{mM}$ EDTA) supplemented with $2 \mathrm{mM}$ DTT, $100 \mu \mathrm{M}$ PMSF, and a protease inhibitor cocktail (containing $1 \mu \mathrm{g} / \mathrm{ml}$ of leupeptin, antipain, chymostatin, and pepstatin A), and ruptured by 30 passages through a 27 -gauge needle. The cell suspension was then rapidly frozen/thawed three times in liquid nitrogen and kept at $-80^{\circ} \mathrm{C}$ until used. Protein content was assayed using the Bradford method. To measure caspases-3- and caspases9-like activity, aliquots of cell extracts containing $25 \mu \mathrm{g}$ 
(for caspase 3) or $50 \mu \mathrm{g}$ (for caspase 9), total protein were incubated in a reaction buffer containing $25 \mathrm{mM}$ HEPES (pH 7.4), 10\% sucrose, $10 \mathrm{mM} \quad$ DTT, $0.1 \%$ 3[(3-cholamidopropyl)dimethylammonio]-propanesulfonic acid, and $100 \mu \mathrm{M}$ caspase substrate (Ac-DEVD$p$ NA for caspase 3 or Ac-LEHD- $p$ NA for caspase 9) for $2 \mathrm{~h}$ at $37^{\circ} \mathrm{C}$. Caspase-like activities were determined by following the detection of the chromophore $p$-nitroanilide after cleavage from the labeled substrate Ac-DEVD- $p$-nitroanilide or Ac-LEHD- $p$-nitroanilide. The method was calibrated with known concentrations of $p$-nitroanilide.

LDH measurements The integrity of plasma membrane was determined by monitoring the activity of cytoplasmic enzyme LDH in the extracellular incubation medium, which represents a common procedure to determine membrane leakage and cellular damage. Assessment of intracellular LDH was determined after lysing the cells with $10 \mathrm{mM}$ HEPES ( $\mathrm{pH}$ 7.4) plus $0.01 \%$ Triton $\mathrm{X}-100$ and freezing at $-80^{\circ} \mathrm{C}$. Cell debris in both aliquots (intracellular and extracellular) were removed by centrifugation at $14,000 \mathrm{rpm}$ for $10 \mathrm{~min}$. LDH activity was determined spectrophometrically (Jasco V-560, Jasco Corporation) by following the rate of conversion of reduced nicotinamide adenine dinucleotide at $340 \mathrm{~nm}$, according to the method of
Bergmeyer and Bernt (Bergmeyer and Bernt 1974). LDH released into the extracellular medium was expressed as a percentage of the total LDH activity in the cells $[\%$ of $\mathrm{LDH}$ released = extracellular $\mathrm{LDH} /$ (extracellular LDH + intracellular LDH)].

Statistical analysis Data are expressed as mean \pm SEM for the number of experiments indicated in the legends of the figures. Multiple comparisons were performed using one-way analysis of variance followed by a Bonferroni post hoc test. Significance was accepted with $p$ value $<0.05$.

\section{Results}

H9c2 myoblasts are spindle-to-stellate-shaped cells that can be mono- or multi-nucleated (Fig. 1a). Treatment with a low Dox concentration $(1 \mu \mathrm{M})$ for $24 \mathrm{~h}$ leads to alterations in cell shape, which include cell shrinkage starting from the periphery and accompanied by membrane blebbing (Fig. 1b); rounding-up of cells, which is also accompanied by membrane blebbing (Fig. 1c); and the appearance of cells with multiple constrictions (Fig. 1d). H9c2 myoblasts treated with supra-physiological dosages
Fig. 1 Morphologic alterations in $\mathrm{H} 9 \mathrm{c} 2$ cells induced by doxorubicin treatment. a DIC images from untreated cells, showing normal membrane morphology. b-d DIC images from cells treated with $1 \mu \mathrm{M}$ Dox for $24 \mathrm{~h}$. All four panels are the same magnification. Scale bar corresponds to $20 \mu \mathrm{m}$
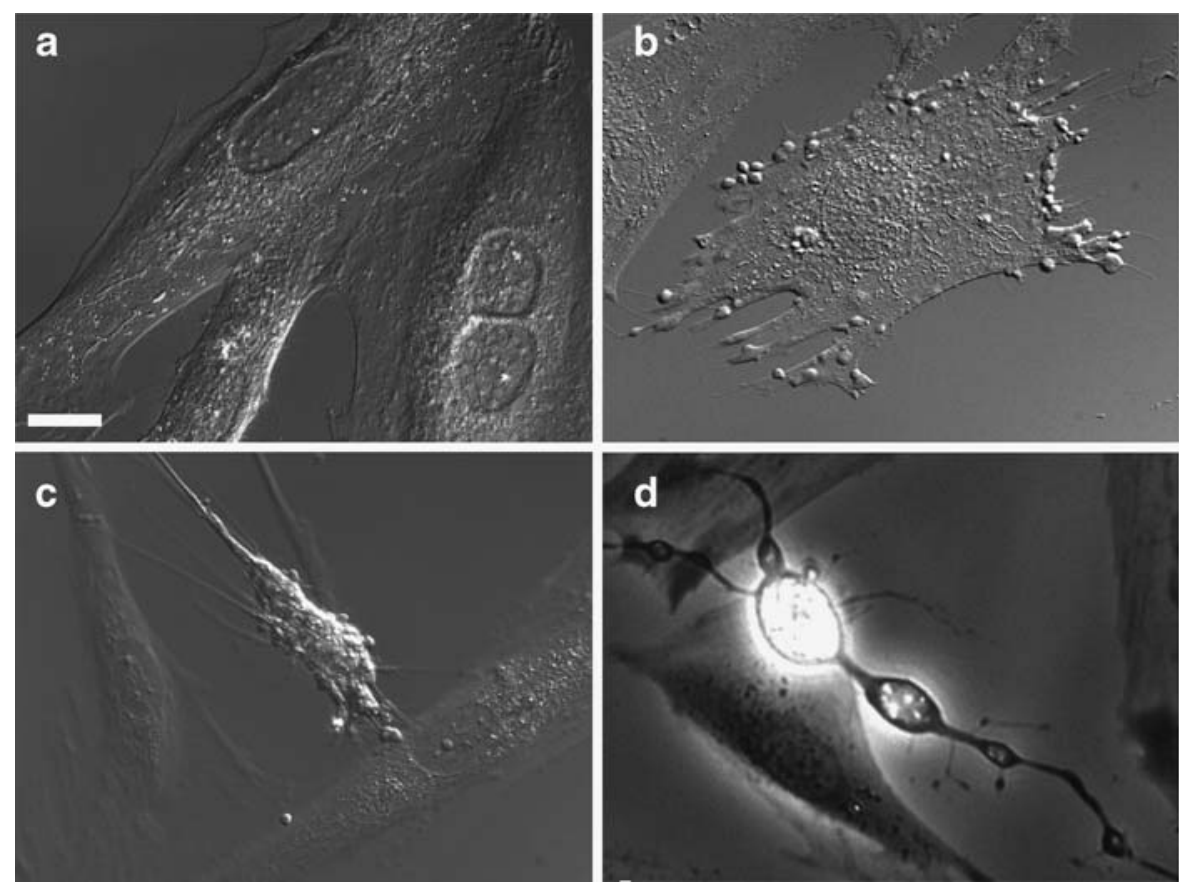
of Dox (5-50 $\mu \mathrm{M})$ become vacuolated (Fig. 2a-d). By using calcein-AM as a probe for cell viability, it was observed that such cells still retain fluorescent calcein, although the fluorophore was excluded from the vacuoles (data not shown).

By using confocal microscopy (Fig. 3), alterations in mitochondrial morphology were evaluated using TMRM and correlated with cell viability by visualization of intracellular calcein fluorescence. Figure $3 \mathrm{a}$ shows control H9c2 myoblasts with intact cell membranes and filamentous polarized mitochondria. Treatment with $1 \mu \mathrm{M}$ Dox causes the appearance of membrane blebbing, which is accompanied by break- age of the mitochondrial network (Fig. 3b). A concentration of Dox as low as $0.5 \mu \mathrm{M}$ promoted the same basic alterations (data not shown). An event that seems common to most cells is mitochondrial depolarization induced by Dox, as assessed by loss of the mitochondrial TMRM signal observed by epifluorescence microscopy (Fig. 3c-n). It is interesting that, even for the highest Dox concentrations tested (20 and $50 \mu \mathrm{M})$, the mitochondrial network still accumulates TMRM, demonstrating the retention of a transmembrane electric potential (Fig. $3 \mathrm{~m}-\mathrm{p}$ ). Interestingly, most of the mitochondrial alterations occur while cells retain green calcein fluorescence, thus remaining viable.
Fig. 2 Doxorubicin induces cytoplasm vacuolization for supra-therapeutic concentrations. Top DIC images from a cells untreated and cells treated with $10 \mu \mathrm{M}$ (b), $20 \mu \mathrm{M}$ (c), and $50 \mu \mathrm{M}$ (d) Dox. All panels are the same magnification. Scale bar corresponds to $20 \mu \mathrm{m}$. Images are representative from three different cell preparations. Bottom Statistical analysis of the population of control and treated cells showing intracellular vacuolization. Analysis was performed by counting cells showing vacuolization and is expressed as the percentage of total cells counted. Data represents the mean \pm SEM of five different experiments. Statistical analysis: ${ }^{*} p<0.05$ vs. control
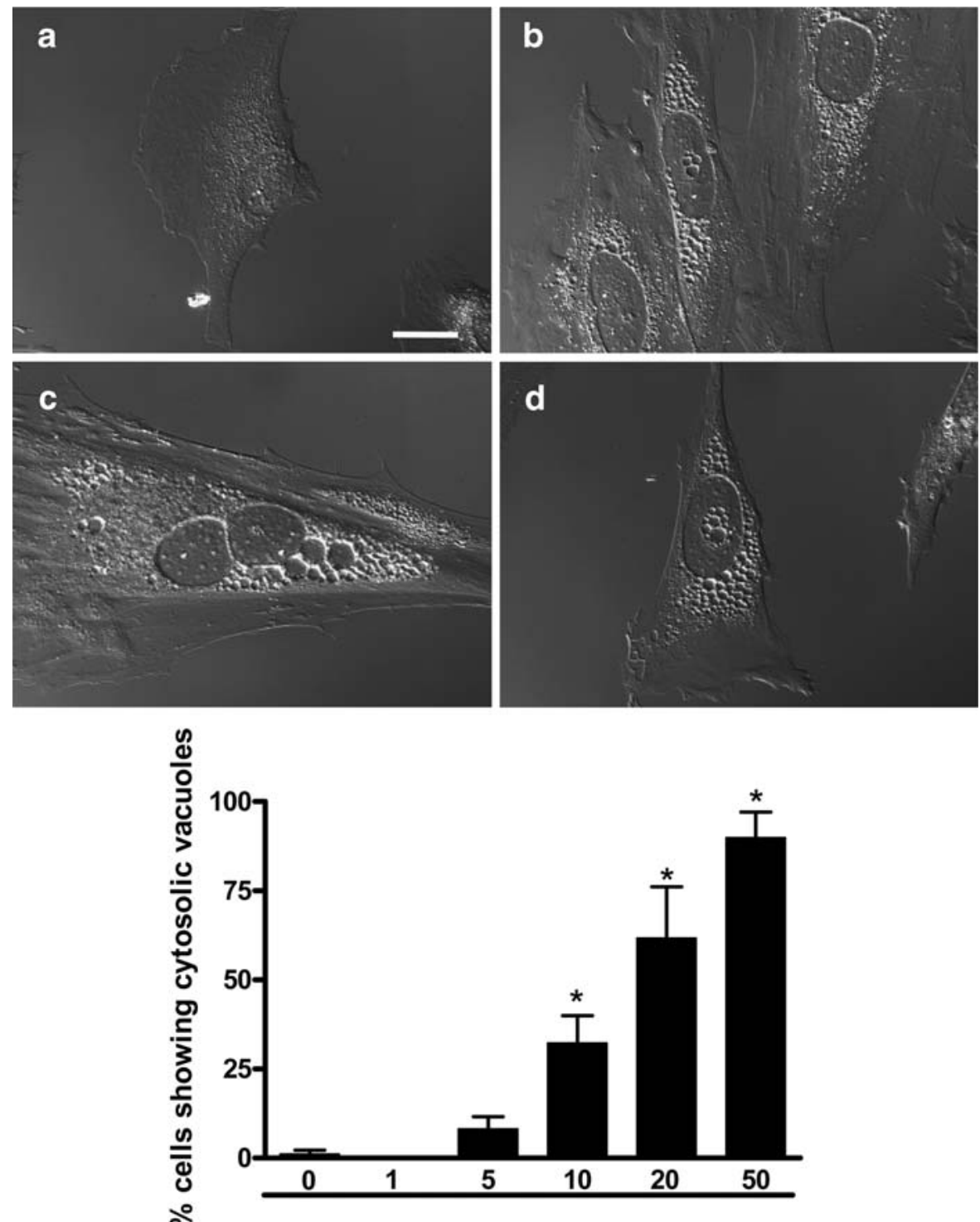

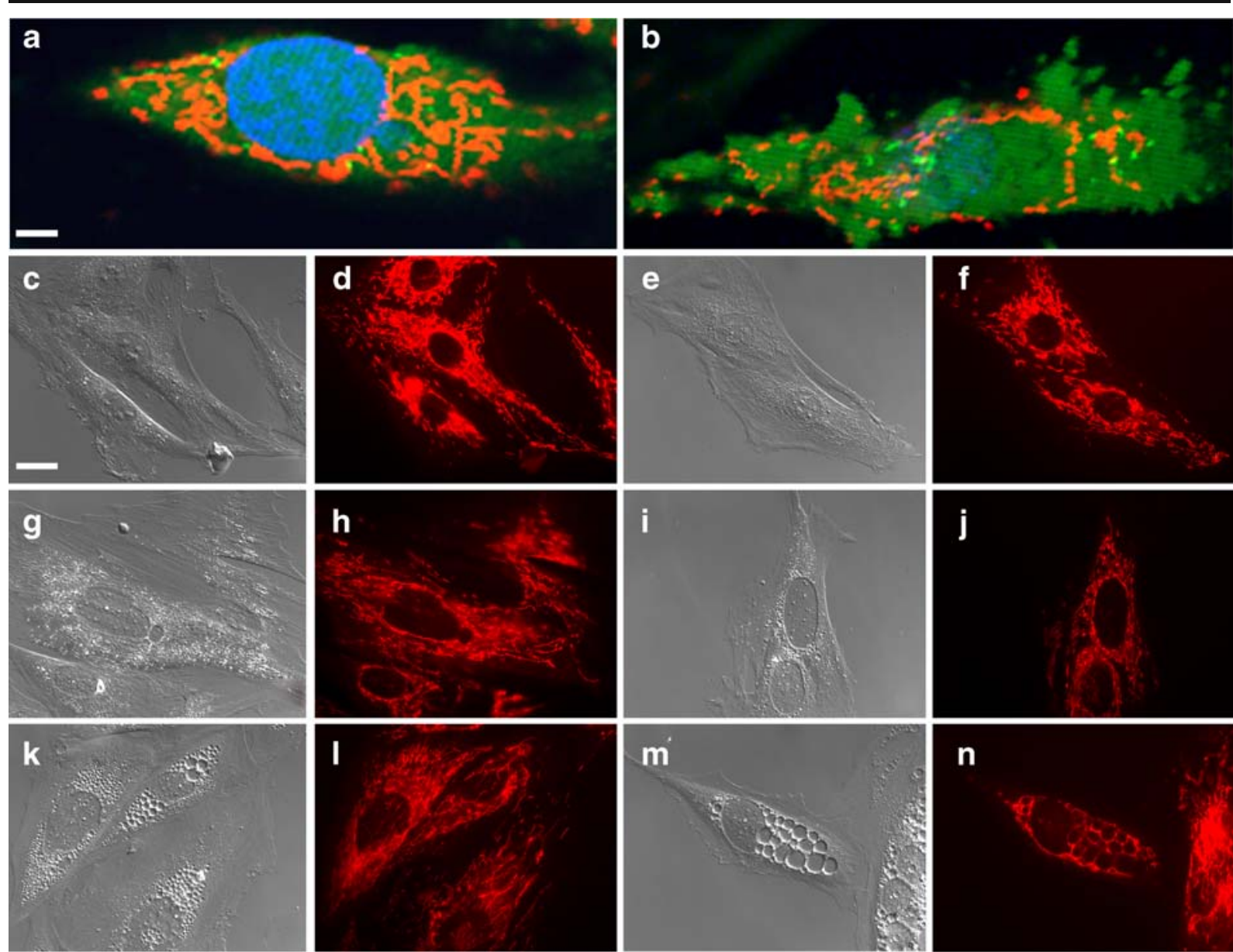

Fig. 3 Mitochondrial alterations in H9c2 cells induced by doxorubicin treatment. a Laser scanning confocal microscopy image from untreated cells showing triple labeling with Hoechst 33342 (blue), calcein-AM (green), and TMRM (red). b Laser scanning confocal microscopy showing the fluorescence of the three dyes after $24 \mathrm{~h}$ treatment with $1 \mu \mathrm{M}$ Dox. Note that part of the mitochondrial network is fragmented in Dox-treated cells. c, d DIC and TMRM fluorescence of control cells. e-n DIC and TMRM fluorescence of cells treated with either $1 \mu \mathrm{M}(\mathbf{e}, \mathbf{f}), 5 \mu \mathrm{M}(\mathbf{g}, \mathbf{h}), 10 \mu \mathrm{M}(\mathbf{i}, \mathbf{j}), 20 \mu \mathrm{M}(\mathbf{k}, \mathbf{l})$, or

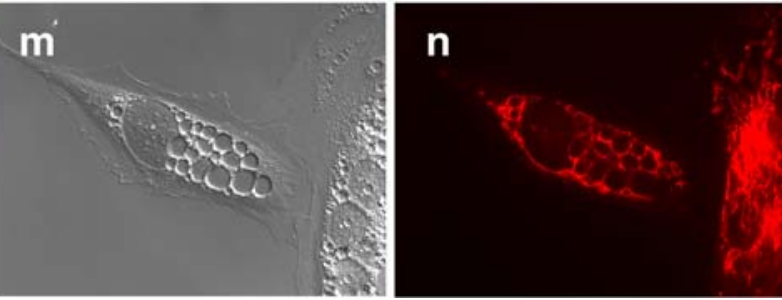

$50 \mu \mathrm{M}(\mathbf{m}, \mathbf{n})$ Dox. Images are representative from three to five different experiments. Note that TMRM fluorescence appears to be diminished with increasing concentrations of Dox; nevertheless, mitochondrial still maintain some degree of membrane polarization as evidenced by their ability to stain with TMRM. Subpanels a and $\mathbf{b}$ are the same magnification; the scale bar in a equals $5 \mu \mathrm{m}$. Subpanels e-n are the same magnification; the scale bar in e equals $20 \mu \mathrm{m}$. c-n Obtained by epifluorescence microscopy

To determine whether morphological changes induced by lower Dox concentrations are associated with changes in fibrous structural proteins, myosin IIB, cardiac myosin, and F-actin organization were examined in control and Dox-treated cells using confocal microscopy. Exposure to $1 \mu \mathrm{M}$ Dox for $24 \mathrm{~h}$ did not noticeably alter the appearance of F-actin and myosin IIB. In contrast, the filamentous organization of cardiac sarcomeric myosin was altered at both 0.5 and $1 \mu \mathrm{M}$ Dox (Fig. 4). At these concentrations, Dox causes granulation and disorganization

of cardiac sarcomeric myosin in a number of cells. It is interesting to note that the effects with $0.5 \mu \mathrm{M}$ Dox were more drastic than with $1 \mu \mathrm{M}$ Dox, which can be explained by protocol limitations, as detached cells with more severe damage could not be imaged.

Nuclear alterations induced by Dox exposure were also explored in the present work. Higher concentrations of Dox cause an increase in the area of cell nuclei, which is statistically significant for 5 and $10 \mu \mathrm{M}$ Dox (Fig. 5). The increase in nuclear area is clearly observable by microscopy (Fig. 5a-d) and is 

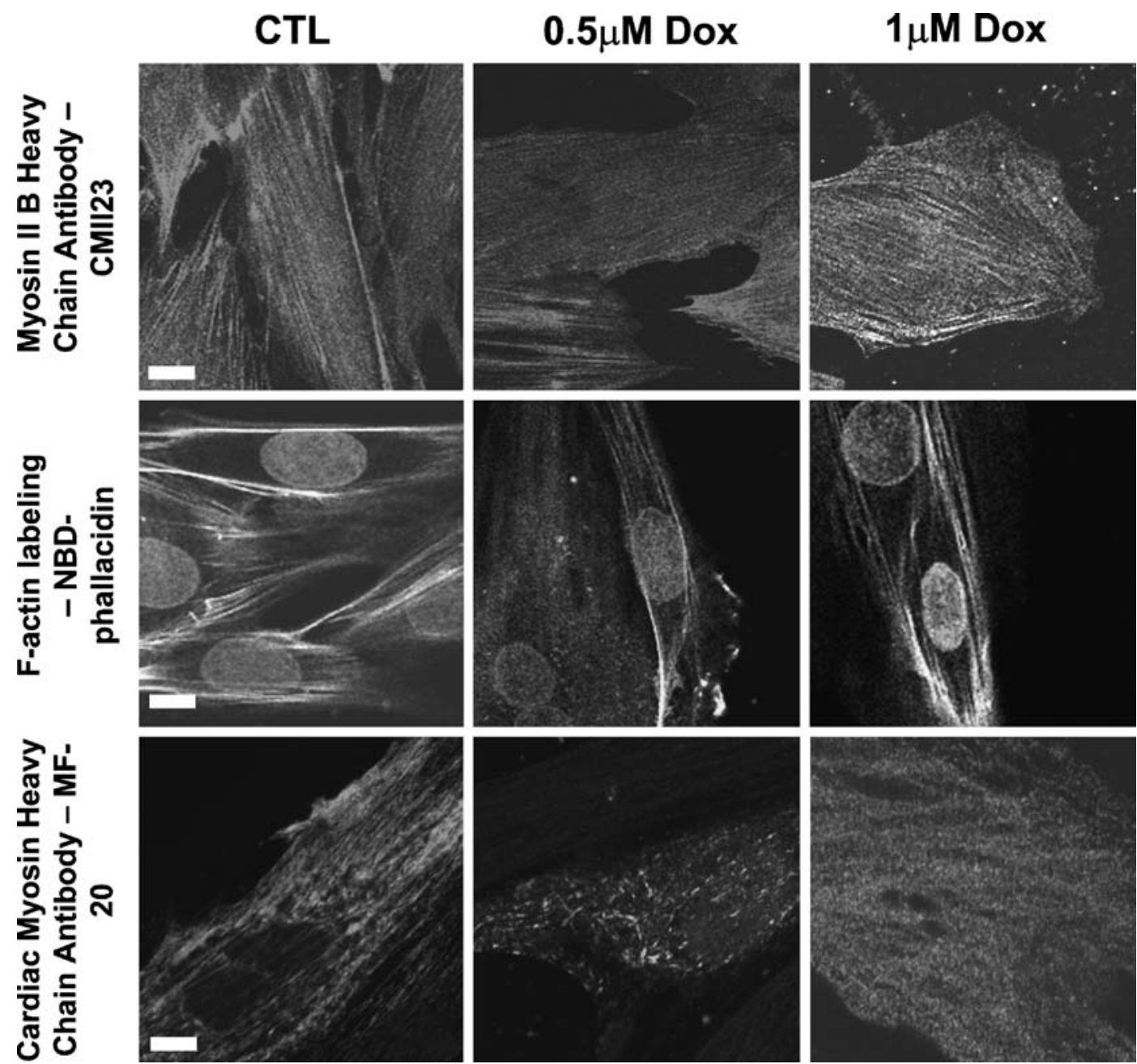

Fig. 4 Alterations of structural proteins induced by doxorubicin in H9c2 cells. Confocal microscopy of the control and Doxtreated $(0.5$ and $1 \mu \mathrm{M}) \mathrm{H} 9 \mathrm{c} 2$ cells. After $24 \mathrm{~h}$ treatment, cells were fixed and labeled with antibodies against myosin IIB heavy chain (CMII23) and cardiac sarcomeric myosin heavy chain $(M F-20)$ or stained with NBD-phallacidin for F-actin labeling. Cells were also counterstained with Hoechst for nuclei labeling. Note that, although the structure of cardiac sarcomeric myosin is disrupted, myosin IIB and f-actin are essentially unaltered for the concentrations tested. Images are representative from three different cell preparations. Scale bar corresponds to $20 \mu \mathrm{m}$ accompanied by what appears to be nucleoli disorganization/dissolution (compare (Fig. 5a and d). An increase in nuclear area was observed regardless the degree of vacuolization shown by cells. Chromatin condensation, a typical marker of apoptosis, was also observable in some cells that appeared to be undergoing apoptosis (data not shown).

We then investigated whether the nuclear changes were accompanied by alterations in the nuclear lamina. Disruption of the lamina was detected after a $24 \mathrm{~h}$ exposure to $1 \mu \mathrm{M}$ Dox (Fig. 6). Changes in lamin organization involved both lamin B1 and lamin
A/C. Alterations of the lamin structure are suggestive of discontinuities or holes in the lamina meshwork, indicating that Dox disrupts the organization of lamins, either directly or as a consequence of cell death processes.

Electron microscopy was used to gain insight into structural changes caused by exposure to Dox for $24 \mathrm{~h}$. For the lowest Dox concentration tested $(0.5 \mu \mathrm{M})$, no significant ultrastructural alterations were found (Fig. 7a-d). Cells treated with $1 \mu \mathrm{M}$ Dox began to show mitochondrial alterations, including enlargement and matrix disorganization (Fig. $7 \mathrm{f}$ 
Fig. 5 Alteration in nucleus area in $\mathrm{H} 9 \mathrm{c} 2$ cells treated with doxorubicin. Top panel DIC images of control H9c2 cells (a) or treated with 1 (b), 5 (c), and $10 \mu \mathrm{M}$ (d) Dox for $24 \mathrm{~h}$, showing an increase in nucleus size. Images are representative from four different experiments. All images are the same magnification; scale bar $=20 \mu \mathrm{m}$. Bottom panel Statistical analysis of the population of control cells or cells treated with increasing concentrations of Dox for $24 \mathrm{~h}$, showing an increase in nuclear area. Data analysis was performed by quantifying nuclear area as square pixels. Data represent the mean \pm SEM of four different cell preparations. Statistical analysis: ${ }^{*} p<0.05$ vs. untreated cells
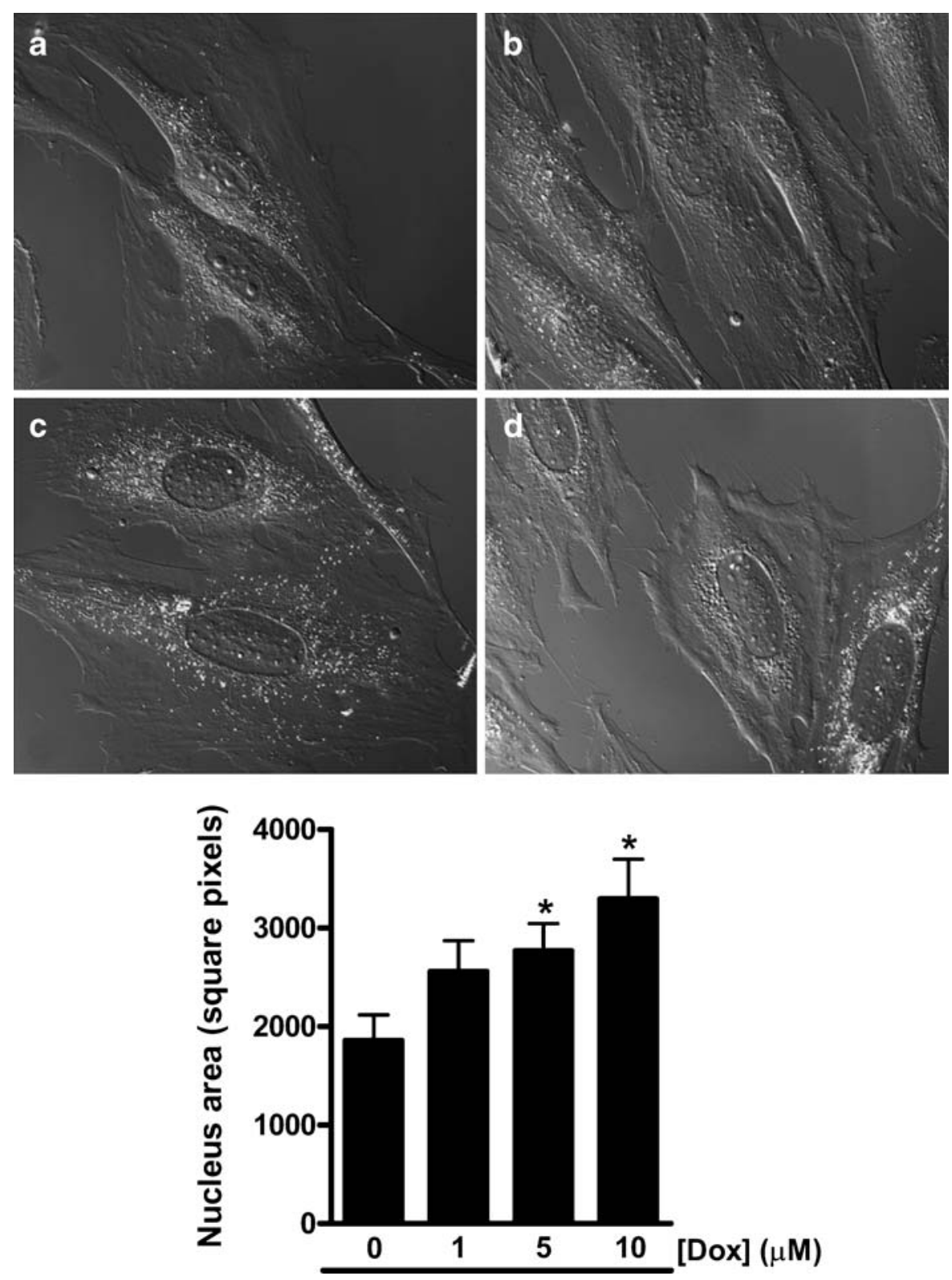

and 1). Cells treated with $20 \mu \mathrm{M}$ Dox revealed loss of mitochondrial cristae (Fig. 7g,h, and $\mathrm{m}$ ) and nuclear disorganization. Cytosolic vacuoles (Fig. 7g) become apparent at this concentration. The highest Dox concentration used $(50 \mu \mathrm{M})$ is characterized by visible cytoplasmic vacuoles and significant nuclear alterations, which include chromatin decondensation and disruption of the nuclear envelope (Fig. 7i,j,o). For these high concentrations, mitochondria again show generalized alterations, including cristae disarray and swelling.
To correlate morphological alterations with biochemical changes in $\mathrm{H} 9 \mathrm{c} 2$ myoblasts, we investigated if apoptotic markers, including PS exposure and caspase activation, were present in cells treated with different Dox concentrations. To examine whether PS exposure occurs in $\mathrm{H} 9 \mathrm{c} 2$ cells after Dox treatment, control and treated cultures were dual-labeled with annexin V and PI. Because PI is excluded from cells with intact plasma membranes, it was used to determine whether annexin $\mathrm{V}$ labeling was due to externalization of PS or instead resulted from a loss of 
Fig. 6 Alteration of nuclear lamina induced by doxorubicin treatment. Epifluorescence microscopy of $\mathrm{H} 9 \mathrm{c} 2$ nucleus after treating cells with $1 \mu \mathrm{M}$ Dox for $24 \mathrm{~h}$. After treatment, cells were fixed and labeled with antibodies against lamin $\mathrm{A} / \mathrm{C}$ and lamin B. Images are representative from three different cell preparations. Scale bar corresponds to $10 \mu \mathrm{m}$

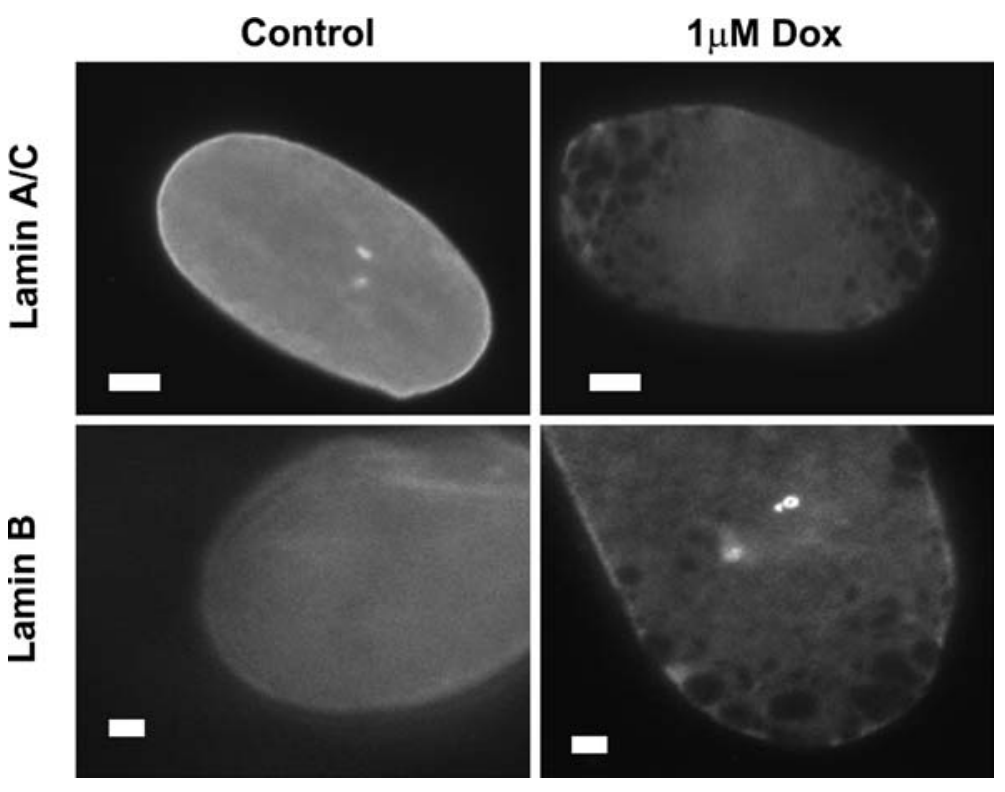

membrane integrity. Dox causes the appearance of PS in the outer leaflet of the cell membrane as early as $6 \mathrm{~h}$ after addition (Fig. 8), showing an increase from $4 \%$ in the control to $14.5 \%$ in cells treated with $0.5 \mu \mathrm{M}$ Dox and to $27.8 \%$ after treatment with $1 \mu \mathrm{M}$ Dox. Only the treatment with $1 \mu \mathrm{M}$ Dox was statistically significant. Less than $1 \%$ of the cells showed PI labeling, indicating that membrane integrity is maintained in apoptotic cells at this time point. However, for a longer exposure time $(12 \mathrm{~h})$, necrotic/ late-apoptotic cells are detected by PI staining, showing an increase from $0 \%$ in control to $2.7 \%$ after $0.5 \mu \mathrm{M}$ Dox treatment and to $5.0 \%$ in cells treated with $1 \mu \mathrm{M}$ Dox, although the differences were not statistically significant. However, for this time point, an increase in the percentage of cells showing annexin $\mathrm{V}$ labeling after Dox treatment was also observable. A significant increase of $31.6 \%$ and $27.3 \%$ was observed after treatment with 0.5 and $1 \mu \mathrm{M}$ Dox, respectively. The present results confirm that Dox at low concentrations causes PS exposure typical of apoptosis in H9c2 myoblasts. In contrast, cells undergoing necrosis appear to be a small minority at these Dox concentrations and time points. LDH release assays confirmed that, at lower Dox concentrations, cell membrane intactness (suggesting necrosis) is only compromised for $1 \mu \mathrm{M}$ (Fig. 9c, $12.5 \pm 3.4 \%$ vs. $23.2 \pm 1.8 \%$ release). The results from Fig. $9 \mathrm{c}$ also demonstrate that, for 5 and $10 \mu \mathrm{M}$ Dox, no further enhancement in the percentage of $\mathrm{LDH}$ release was observed. No LDH release was detected for any concentration tested when cells were treated for 6 and 12 h. By using epifluorescence microscopy, the presence of necrotic cells was confirmed by the absence of calcein accumulation and increased nuclear labeling with ethidium homodimer (data not shown).

Caspases were activated upon treatment with Dox, not only for lower $(1 \mu \mathrm{M})$ but also for higher Dox concentrations (5 and $10 \mu \mathrm{M}$ ), especially for a 24$\mathrm{h}$ incubation period (Fig. 9a and b). For a 6-h time period, an increase in caspase 9 activity was only observed after treatment with $10 \mu \mathrm{M}$ Dox. In contrast, no caspase 3 activity was detected for this time point regardless of the Dox concentration used. However, after $12 \mathrm{~h}$ treatment, an increase in the activity of both caspases 3 and 9 was observed for all Dox concentrations tested.

\section{Discussion}

Doxorubicin is a potent antineoplastic agent whose clinical use is restricted by a cumulative and serious cardiac toxicity. Numerous studies have been performed to understand why Dox is selectively cardiotoxic. In vivo models of Dox-induced cardiomyopathy (Oliveira and Wallace 2006; Santos et al. 2002) and in 
Fig. 7 Electron microscopy of $\mathrm{H} 9 \mathrm{c} 2$ cells after $24 \mathrm{~h}$ treatment with doxorubicin. a and b Control; $\mathbf{c}$ and d $0.5 \mu \mathrm{M}$ Dox; $\mathbf{e}$ and $\mathbf{f}$ $1 \mu \mathrm{M}$ Dox; g and h $20 \mu \mathrm{M}$ Dox; i and j $50 \mu \mathrm{M}$ Dox. $\mathbf{k}-\mathbf{m}$ Comparison of mitochondria from control cells (k) and cells treated with $1 \mu \mathrm{M}$ (l) and $50 \mu \mathrm{M}(\mathbf{m})$ Dox. $\mathbf{n}$ and $\mathbf{o}$ Comparison of nuclear envelope morphology between control cells (n) and cells treated with $50 \mu \mathrm{M}$ Dox (o). Note the discontinuity of the nuclear envelope and the decondensed appearance of the chromatin in $\mathbf{j}$ and $\mathbf{o}$. Subpanels a, c, e, $\mathbf{g}$, and $\mathbf{i}$ have the same magnification (bar corresponds to $4 \mu \mathrm{m}$ ). The white bar in b corresponds to $7.5 \mu \mathrm{m}$, which is the same magnification as $\mathbf{d}$, $\mathbf{f}, \mathbf{h}$, and $\mathbf{j}$. Subpanels $\mathbf{k}-\mathbf{m}$ are the same magnification (bar equals $2 \mu \mathrm{m}$ ). Bar in $\mathbf{n}$ equals to $1 \mu \mathrm{m}$ (same magnification of $\mathbf{o}$ ). $n$ nucleus, $m$ mitochondria, $v$ vacuole. The white arrow in $i$ points to disruption of the nuclear membrane
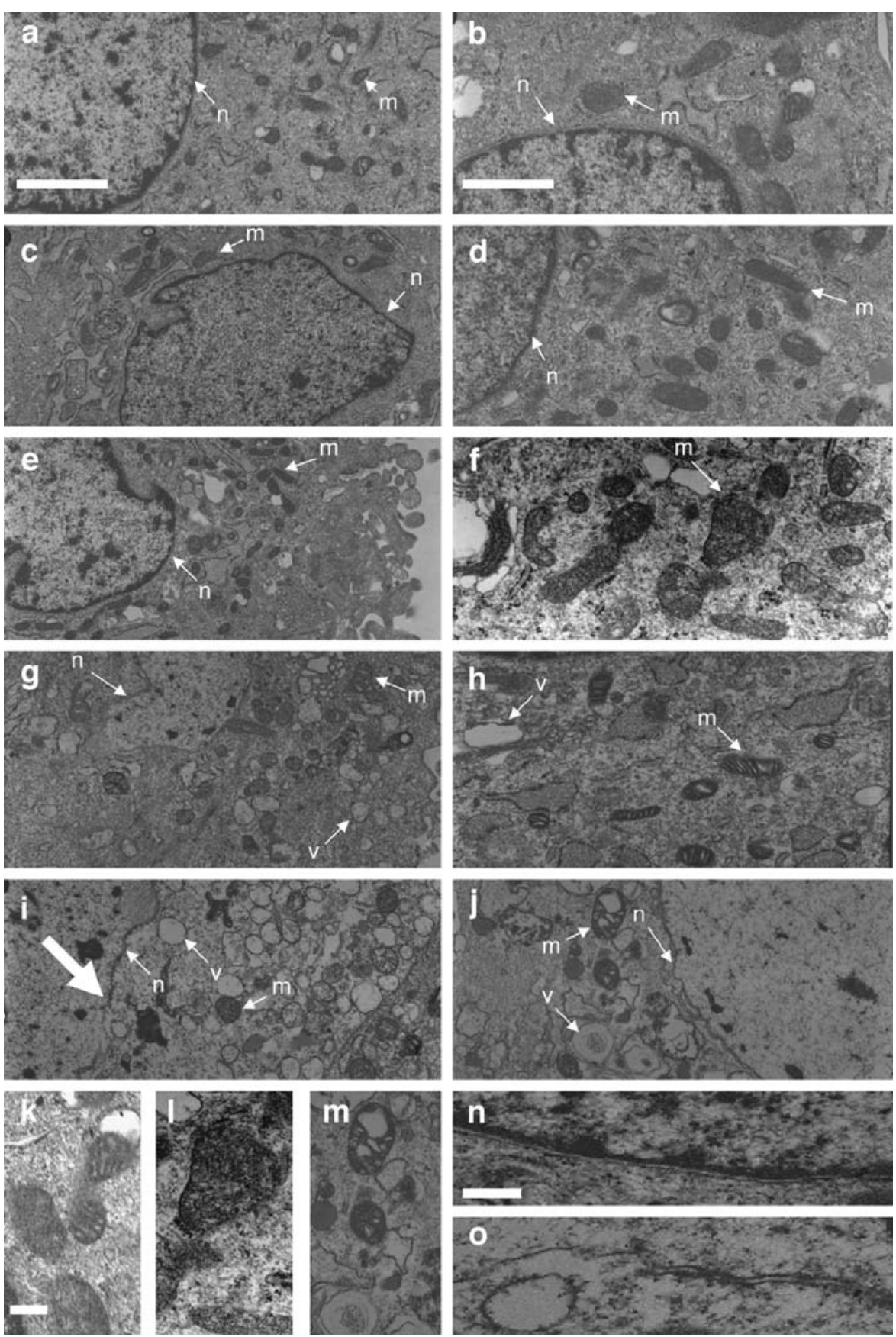

vitro studies using primary cardiomyocytes (Gabrielson et al. 2007; Solem et al. 1996; Zhou et al. 2001) or other cell lines (L'Ecuyer et al. 2001; Spallarossa et al. 2004) have been widely reported in the literature. From the different models used, some conclusions are common to all: (a) Dox is activated at the mitochondrial level, forming a semiquinone radical, and (b)
Dox causes oxidative stress in cardiac cells that particularly affects mitochondria (Berthiaume and Wallace 2007; Wallace 2003).

One of the cell lines used to study Dox toxicity is the myoblastic cell line $\mathrm{H} 9 \mathrm{c} 2$, originally derived from embryonic rat heart tissue by using selective serial passages (Kimes and Brandt 1976). H9c2 cells have 


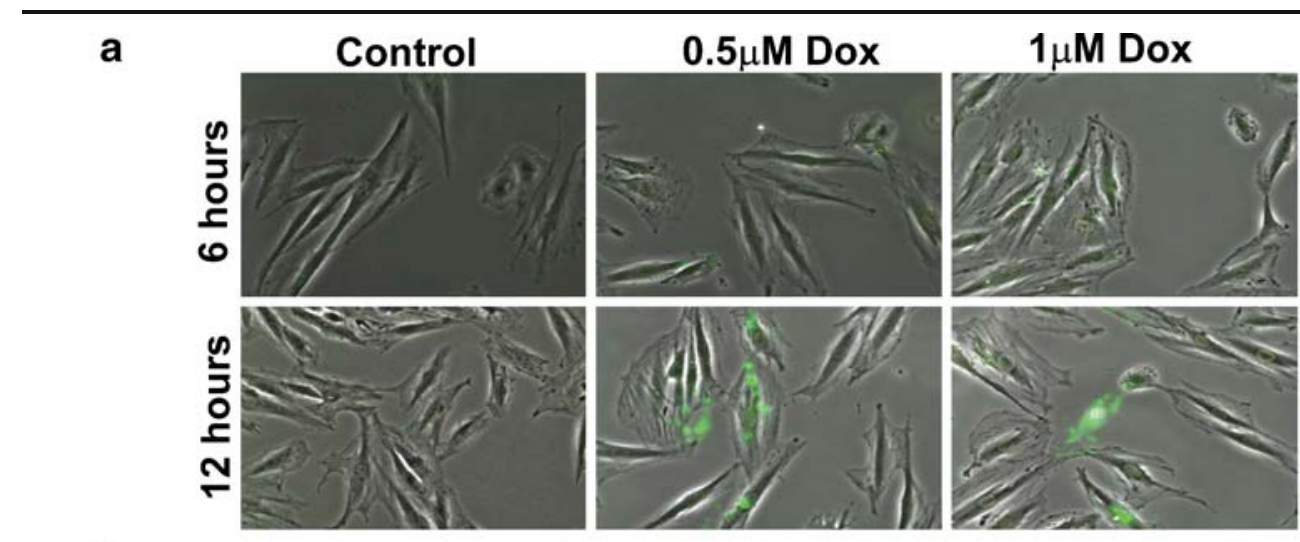

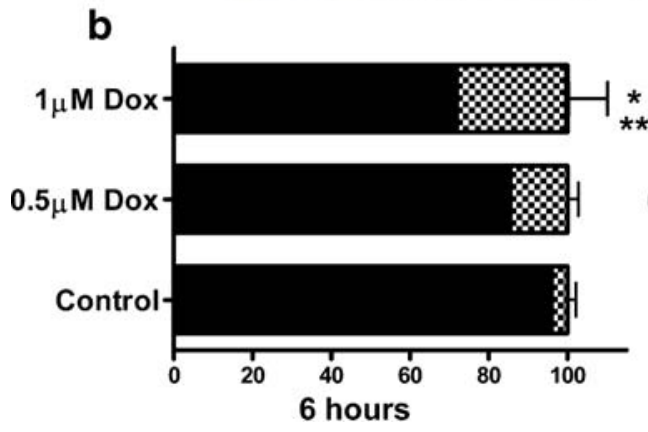

Fig. 8 Doxorubicin induces the translocation of phosphatidylserine to the outer leaflet of the cellular membrane. a After 6 and $12 \mathrm{~h}$, the control and Dox-treated $(0.5$ and $1 \mu \mathrm{M})$ cells were labeled with Annexin V and propidium iodide. Panels represent phase contrast images of $\mathrm{H} 9 \mathrm{c} 2$ cells merged with corresponding epifluorescence microscopy images of propidium iodide (red) and Annexin V (green). Images are representative from three separate experiments. All images have the same magnification; scale bar $=20 \mu \mathrm{m}$. b Statistical analysis of the population of

been used to study several aspects of Dox interaction with cardiac cells, including the intracellular degradation of the anthracycline (Menna et al. 2007), DNA damage induced by Dox (L'Ecuyer et al. 2006), or p53 activation (Chua et al. 2006) among others. On the other hand, this same cell line has been used as a model to investigate the protective effect of several compounds against Dox-induced cardiotoxicity. Among such compounds, carvedilol (Spallarossa et al. 2004), rosmarinic acid (Kim et al. 2005), plantainoside D (Kim et al. 2007), or thrombopoietin (Li et al. 2006) are particular examples.

Despite biochemical data gathered on signaling pathways involving Dox-induced H9c2 cell dysfunction, relatively little is known regarding alterations in cell morphology. It was the objective of the present work to conduct an investigation on the morphological alterations that H9c2 myoblasts display upon Dox treatment. For this purpose, several Dox concentrations were used in the present study. The lowest ones $(0.5$ and $1 \mu \mathrm{M})$ can be considered clinically relevant because they fall well within the concentrations of Dox found in the plasma of patients undergoing Dox therapy (Frost et al. 2002). Intermediary concentrations such as 5 and $10 \mu \mathrm{M}$ are unlikely to be achieved in vivo, except in individuals with low drug clearance or immediately after drug administration (Frost et al. 2002; Palle et al. 2006). Finally, 20 and $50 \mu \mathrm{M}$ are largely supra-physiological concentrations of Dox; the main purpose for their use was to investigate if higher drug doses could uncover mechanisms of Doxinduced cytotoxicity that would be harder to detect with lower, more clinically relevant, concentrations.

From the results obtained in the present study, it was confirmed that Dox leads to caspase activation at concentrations up to $10 \mu \mathrm{M}$ (Fig. 9). Caspase 9 is 


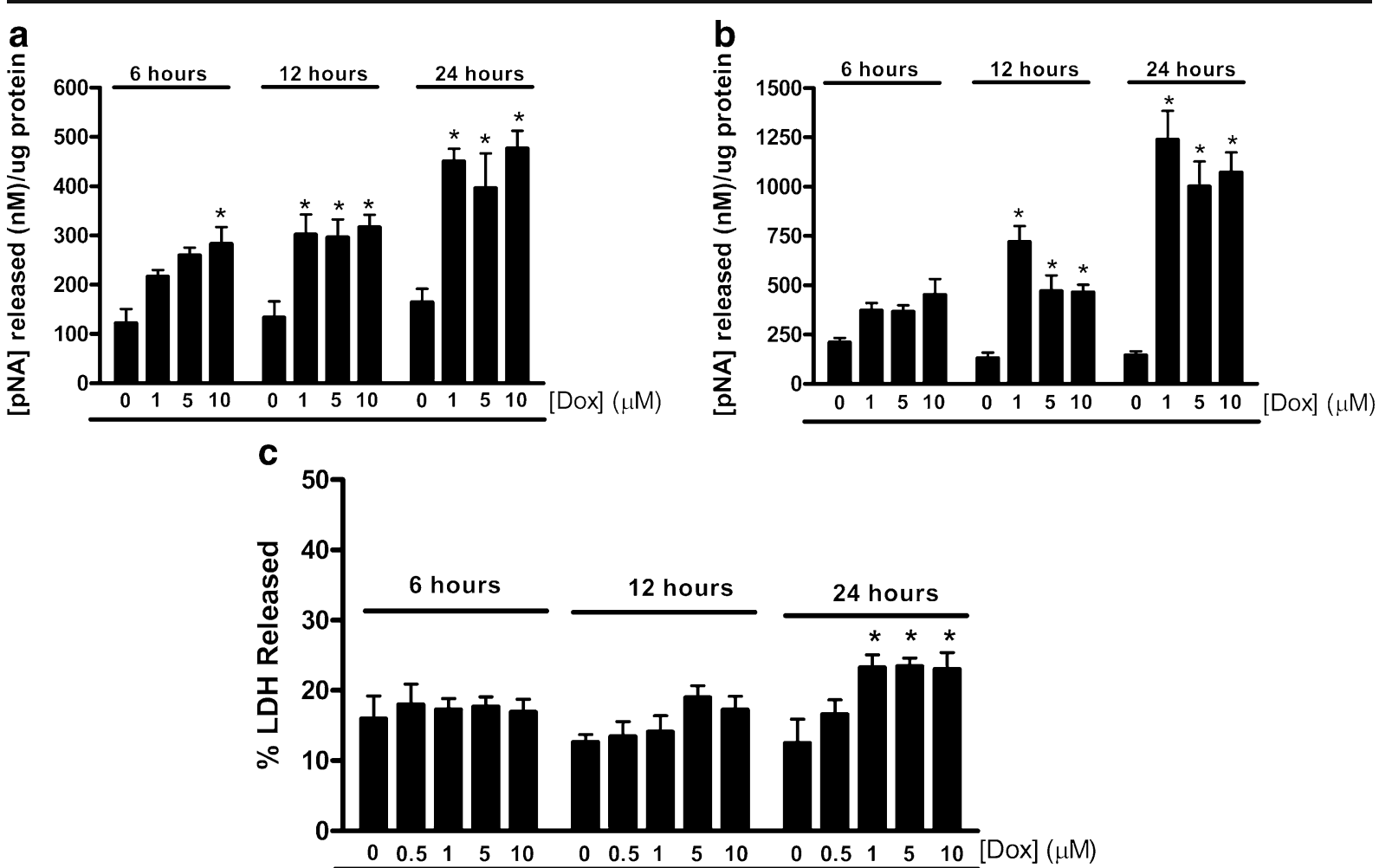

Fig. 9 Incubation of doxorubicin with $\mathrm{H} 9 \mathrm{c} 2$ cells for $24 \mathrm{~h}$ increases caspases-9- and caspases-9-3-like activation and reduces cell viability. Caspase-9- (a) and caspase-3-like (b) activities were measured by following the cleavage of the colorimetric substrates Ac-LEHD- $p$ NA and Ac-DEVD- $p$ NA, respectively. The caspase-like activity was expressed as concentration of $p \mathrm{NA}$ released per microgram protein. The results were calibrated with known concentrations of $p$ NA. c Cellular viability was determined by the LDH leakage assay, as described in the methods section. The results were expressed as percentage of total LDH released and represent the means \pm SEM of six independent experiments. Statistical analysis: ${ }^{*} p<$ 0.05 compared with untreated cells for the same time point

leading mechanism. The sum of results for caspase activity and LDH release regarding $1 \mu \mathrm{M}$ Dox suggest that, for $24 \mathrm{~h}$, a major transition between apoptosis and necrosis occurs.

It was demonstrated that Dox causes profound morphological changes in $\mathrm{H} 9 \mathrm{c} 2$ myoblasts. Rounding up of the cell body, cellular membrane blebbing, and phosphatidylserine (PS) translocation from the inner to the outer leaflet of the plasma membrane are some alterations observed in $\mathrm{H} 9 \mathrm{c} 2$ myoblasts after Dox exposure. In fact, alterations in plasma membrane asymmetry are one of the characteristic features of cells undergoing apoptosis. In apoptotic cells, phosphatidylserine (PS) is translocated from the inner to the outer leaflet of the plasma membrane, serving as a recognition signal for macrophages (Fadeel and Kagan 2003). Such morphological alterations resemble the shape changes displayed by cardiomyocytes (Yue et al. 1998) or H9c2 myoblasts (Sardão et al., 
unpublished data) when incubated with the protein kinase inhibitor staurosporin. Although Yue et al. (1998) reported staurosporin-induced apoptosis in cardiomyocytes with caspase 3 activation, it is likely that different compounds with distinct mechanisms of action may cause similar morphological alterations. The data from the present work also demonstrate for the first time that Dox alters the organization of H9c2 myoblast cardiac sarcomeric myosin. No changes were observed on myosin IIB or f-actin organization. A relation between Dox treatment and alterations in myocardial structural proteins and regulatory protein expression was previously described after in vivo treatment of rats (Dudnakova et al. 2003). It is also possible that Dox directly binds to cardiac myosin, thus altering its normal organization. It is unclear whether the structural disorganization of the filamentous network of cardiac myosin was a cause or consequence of the changes in cell morphology induced by Dox treatment. However, the demonstration that cardiac sarcomeric myosin organization was more noticeably perturbed than myosin IIB or f-actin organization raises the intriguing possibility that cardiac sarcomeric myosin may be a specific target that contributes to the unique sensitivity of cardiac tissue to the toxic effects of Dox.

Among the nuclear effects of Dox treatment, a marked disruption of the nuclear lamina, involving both A- and B-type lamins was observed. Lamins are well-known caspase substrates (Croft et al. 2005), and it is possible that the lamin alterations observed in this study are a reflection of apoptosis (Lieberman and Fan 2003; Prasad et al. 1999). von Harsdorf et al. (1999) detected lamin degradation induced by oxidative stress in isolated cardiac cells, suggesting a link between Dox-induced oxidative stress and degradation of the nuclear lamins. Lamins are interesting putative Dox targets for a number of reasons. Mutations in lamin A/C are a direct cause of muscular dystrophy, one symptom of which is cardiac dysfunction and pathology (Ben Yaou et al. 2006; Muntoni 2003). However, lamin A/C mutations usually take a number of years to result in mortality (Perrot et al. 2006), which is not unlike the delayed and cumulative nature of Dox cardiotoxicity. Nuclear lamin function has been linked to the regulation of DNA organization, DNA synthesis, and gene expression, and it has been suggested that disruptions in the nuclear lamina can have long-term effects on overall gene expression patterns in cells (Bridger et al. 2007). Also, mutations in lamins can lead to progeria or premature aging syndromes (Dechat et al. 2007). It appears that Dox interaction with nuclear lamins is worth further attention.

Another nuclear-associated Dox effect was an increase in nuclear area. This increase was visible for $5 \mu \mathrm{M}$ Dox, which is within the upper limits of Dox concentrations normally found in the plasma of patients (Frost et al. 2002; Palle et al. 2006). Similar nuclear swelling has been described after etoposide treatment of neuronal cells (Kim et al. 2001); like Dox, etoposide is known to have topoisomerase II inhibitory activity. Changes in nuclear morphology, including chromatin decondensation, were also observed by electron microscopy (EM). Dox has been reported to produce both an unfolding of the overall chromatin structure as evidenced by the increased production of acid-soluble oligonucleotides and a disruption of the core particle structure with increased production of DNA of subnucleosomal size and smearing of the nucleosome pattern (Grimmond and Beerman 1982). The observation may explain the profound nuclear alterations induced by higher Dox concentrations. Rupture of the nuclear envelope was also observed starting at $10 \mu \mathrm{M}$ Dox. Changes in nuclear envelope morphology may be related to the effects of Dox on the lamina noted above.

Mitochondria are known targets of Dox; in vivo studies (Santos et al. 2002) demonstrate that Dox induces mitochondrial swelling in cardiac tissue. In the present study, although $0.5 \mu \mathrm{M}$ Dox did not promote significant mitochondrial alterations as observed by electron microscopy, $1 \mu \mathrm{M}$ Dox caused structural alterations in a subset of mitochondria, which included organelle enlargement. Morphological changes are more evident at higher Dox concentrations, where cristae content is reduced and severely damaged mitochondria are observed. In fact, it was difficult to distinguish by EM the difference between the vacuoles found for higher Dox concentrations and swollen mitochondria (see Fig. 7j). By using confocal and epifluorescence microscopy to investigate mitochondrial alterations during Dox incubation, it is concluded that Dox causes (a) mitochondrial depolarization and (b) fragmentation of mitochondrial filaments, both of which are more common in cells displaying membrane blebbing (even for the lowest Dox concentration tested). It appears that the abnor- 
mal mitochondrial morphology as observed by electron microscopy is correlated with a reduction in TMRM staining and, thus, a reduction in electric potential. For the largest Dox concentrations used (20 and $50 \mu \mathrm{M})$, although severe mitochondrial damage is observable by electron microscopy, polarized mitochondria can still be found in cells. Mitochondrial swelling can result from induction of the mitochondrial permeability transition (MPT). The MPT is a condition triggered by excessive mitochondrial calcium loading and oxidative stress; one of the final results is mitochondrial swelling due to osmotic equilibrium between the mitochondrial matrix and the cytosol (Rasola and Bernardi 2007). Dox causes oxidative stress in cardiac muscle (Davies and Doroshow 1986), and oxidative stress has previously been shown to induce the MPT in H9c2 myoblast mitochondria (Park et al. 2003). Therefore, it is reasonable to presume that the mitochondrial morphological changes observed in this study arise, at least in part, by the ability of Dox to induce the permeability transition in a mitochondrial sub-population that would be more extensive as Dox concentration increases.

The vacuoles observed at higher Dox concentrations (Fig. 2) could have originated from sarcoplasmic reticulum enlargement (Iwasaki and Suzuki 1991) or produced by autophagic cell death (Yan et al. 2005) triggered by the large Dox concentrations used. In many cell lines, such vacuoles are known to contain products of lipid metabolism or peroxidation (Shimasaki et al. 1984; Terman and Brunk 2005).

In conclusion, the present work describes several morphological alterations displayed by H9c2 myoblasts after Dox treatment. For lower Dox concentrations, which are to be found in patients receiving Dox therapy, Dox causes morphological alterations (e.g., lamin degradation, cardiac sarcomeric myosin disorganization) that occur simultaneously with markers of apoptosis (caspase activation or PS exposure). H9c2 myoblast cells display heterogeneous morphological alterations, although maintaining membrane integrity during the initial stages of the apoptotic process. Higher concentrations of Dox that are in the top-most limit found in the serum of patients (Frost et al. 2002) or that are supraphysiological caused different morphological alterations that include nuclear swelling and the formation of vacuoles. It is pertinent to speculate that the same effects could be attained in vivo using a subchronic or chronic treatment with lower, pharmacological doses due to tissue drug accumulation. In fact, most alterations induced by Dox on H9c2 myoblasts, such as mitochondrial and nuclear damage, cytoplasm vacuolization, alterations in sarcomeric proteins, and apoptosis, are indeed observed in cardiac tissue after in vivo Dox treatment (Grimmond and Beerman 1982; Iwasaki and Suzuki 1991; Jang et al. 2004; Jones et al. 1990; Ueno et al. 2006; Unverferth et al. 1981; Villani et al. 1990).

However, for the first time, the present study describes alterations in sarcomeric protein organization and identifies nuclear lamina proteins as potential Dox-targets; such alterations should be looked for on differentiated mature cardiac myocytes. In fact, one of the limitations of the present work is the fact that the H9c2 cell line is phenotypically distinct from cardiac myocytes, even though they share several properties (Hescheler et al. 1991; Kimes and Brandt 1976). Although this myoblastic cell line shows similar morphological characteristics to immature embryonic cardiomyocytes, it has been shown to retain several electrical and hormonal signaling pathways found in adult cardiomyocytes and is, therefore, a useful model for studying various aspects of cardiomyocyte physiology and pathophysiology (Brostrom et al. 2000; Wayman et al. 2001). One particular question currently under study in our laboratory is if differences in cell proliferation observed in undifferentiated vs. differentiated H9c2 cells can alter the susceptibility to Dox or if these same morphological changes occur in non-cardiac cells exposed to Dox in culture.

Data obtained from the present work complements previous works demonstrating pathways activated or inhibited by Dox on $\mathrm{H} 9 \mathrm{c} 2$ myoblast cells and suggests that previously unknown Dox targets, such as nuclear lamins can contribute to the pathophysiology of Dox cardiotoxicity.

Acknowledgment This work was supported by NIH grant HL 58016 to K.W., by FCT grant PTDC-SAU-OSM-64084-2006 to P.J.O. and by fellowships SFRH/BD/10251/2002 and SFRH/ BPD/8359/2002 from the Portuguese Foundation for Science and Technology to V.S. and P.J.O., respectively.

\section{References}

Ben Yaou R, Gueneau L, Demay L, et al. Heart involvement in lamin A/C related diseases. Arch Mal Coeur Vaiss. 2006;99(9):848-55. 
Bergmeyer HU, Bernt E. Lactate-dehydrogenase, UV-assay with pyruvate and NADH. In: Bergmeyer HU, editor. Methods of enzymatic analysis (vol. 2). New York: Academic; 1974.

Berthiaume JM, Wallace KB. Adriamycin-induced oxidative mitochondrial cardiotoxicity. Cell Biol Toxicol. 2007;23 (1): $15-25$.

Box VG. The intercalation of DNA double helices with doxorubicin and nagalomycin. J Mol Graph Model. 2007;26(1):14-9.

Bridger JM, Foeger N, Kill IR, et al. The nuclear lamina. Both a structural framework and a platform for genome organization. FEBS J. 2007;274(6):1354-61.

Brostrom MA, Reilly BA, Wilson FJ, et al. Vasopressininduced hypertrophy in $\mathrm{H} 9 \mathrm{c} 2$ heart-derived myocytes. Int J Biochem Cell Biol. 2000;32(9):993-1006.

Chua CC, Liu X, Gao J, et al. Multiple actions of pifithrinalpha on doxorubicin-induced apoptosis in rat myoblastic H9c2 cells. Am J Physiol Heart Circ Physiol. 2006;290(6): H2606-13.

Croft DR, Coleman ML, Li S, et al. Actin-myosin-based contraction is responsible for apoptotic nuclear disintegration. J Cell Biol. 2005;168(2):245-55.

Cutts SM, Nudelman A, Rephaeli A, et al. The power and potential of doxorubicin-DNA adducts. IUBMB Life. 2005;57(2):73-81.

Cutts SM, Parsons PG, Sturm RA, et al. Adriamycin-induced DNA adducts inhibit the DNA interactions of transcription factors and RNA polymerase. J Biol Chem. 1996;271 (10):5422-9.

Davies KJ, Doroshow JH. Redox cycling of anthracyclines by cardiac mitochondria. I. Anthracycline radical formation by NADH dehydrogenase. J Biol Chem. 1986;261 (7):3060-7.

Dechat T, Shimi T, Adam SA, et al. Alterations in mitosis and cell cycle progression caused by a mutant lamin A known to accelerate human aging. Proc Natl Acad Sci U S A. 2007;104(12):4955-60.

Dudnakova TV, Lakomkin VL, Tsyplenkova VG, et al. Alterations in myocardial cytoskeletal and regulatory protein expression following a single doxorubicin injection. J Cardiovasc Pharmacol. 2003;41(5):788-94.

Fadeel B, Kagan VE. Apoptosis and macrophage clearance of neutrophils: regulation by reactive oxygen species. Redox Rep. 2003;8(3):143-50.

Frost BM, Eksborg S, Bjork O, et al. Pharmacokinetics of doxorubicin in children with acute lymphoblastic leukemia: multi-institutional collaborative study. Med Pediatr Oncol. 2002;38(5):329-37.

Gabrielson K, Bedja D, Pin S, et al. Heat shock protein 90 and ErbB2 in the cardiac response to doxorubicin injury. Cancer Res. 2007;67(4):1436-41.

Garrido C, Galluzzi L, Brunet M, et al. Mechanisms of cytochrome c release from mitochondria. Cell Death Differ. 2006;13(9):1423-33.

Grimmond HE, Beerman T. Alteration of chromatin structure induced by the binding of adriamycin, daunorubicin and ethidium bromide. Biochem Pharmacol. 1982;31 (21):3379-86.

Hescheler J, Meyer R, Plant S, et al. Morphological, biochemical, and electrophysiological characterization of a clonal cell (H9c2) line from rat heart. Circ Res. 1991;69 (6):1476-86.

Iwasaki T, Suzuki T. Ultrastructural alterations of the myocardium induced by doxorubicin. A scanning electron microscopic study. Virchows Arch B Cell Pathol Incl Mol Pathol 1991;60(1):35-9.

Jang YM, Kendaiah S, Drew B, et al. Doxorubicin treatment in vivo activates caspase-12 mediated cardiac apoptosis in both male and female rats. FEBS Lett. 2004;577(3):48390 .

Jones SM, Kirby MS, Harding SE, et al. Adriamycin cardiomyopathy in the rabbit: alterations in contractile proteins and myocyte function. Cardiovasc Res. 1990;24 (10):834-42.

Joyeux M, Godin-Ribuot D, Faure P, et al. Heat stress protects against electrophysiological damages induced by acute doxorubicin exposure in isolated rat hearts. Cardiovasc Drugs Ther. 2001;15(3):219-24.

Kalyanaraman B, Joseph J, Kalivendi S, et al. Doxorubicininduced apoptosis: implications in cardiotoxicity. Mol Cell Biochem 2002;234-5(1-2):119-24.

Kim DS, Kim HR, Woo ER, et al. Inhibitory effects of rosmarinic acid on adriamycin-induced apoptosis in $\mathrm{H} 9 \mathrm{c} 2$ cardiac muscle cells by inhibiting reactive oxygen species and the activations of c-Jun N-terminal kinase and extracellular signal-regulated kinase. Biochem Pharmacol. 2005;70(7):1066-78.

Kim DS, Woo ER, Chae SW, et al. Plantainoside D protects adriamycin-induced apoptosis in $\mathrm{H} 9 \mathrm{c} 2$ cardiac muscle cells via the inhibition of ROS generation and NF-kappaB activation. Life Sci. 2007;80(4):314-23.

Kim JE, Han BS, Choi WS, et al. Temporospatial sequence of cellular events associated with etoposide-induced neuronal cell death: role of antiapoptotic protein $\mathrm{Bcl}-\mathrm{X}(\mathrm{L})$. J Neurosci Res. 2001;66(6):1074-82.

Kimes BW, Brandt BL. Properties of a clonal muscle cell line from rat heart. Exp Cell Res. 1976;98(2):367-81.

L'Ecuyer T, Horenstein MS, Thomas R, et al. Anthracyclineinduced cardiac injury using a cardiac cell line: potential for gene therapy studies. Mol Genet Metab. 2001;74 (3):370-9.

L'Ecuyer T, Sanjeev S, Thomas R, et al. DNA damage is an early event in doxorubicin-induced cardiac myocyte death. Am J Physiol Heart Circ Physiol. 2006;291(3):H1273-80.

Li K, Sung RY, Huang WZ, et al. Thrombopoietin protects against in vitro and in vivo cardiotoxicity induced by doxorubicin. Circulation. 2006;113(18):2211-20.

Lieberman J, Fan Z. Nuclear war: the granzyme A-bomb. Curr Opin Immunol 2003;15(5):553-9.

Lushnikova EL, Klinnikova MG, Molodykh OP, et al. Morphological manifestations of heart remodeling in anthracycline-induced dilated cardiomyopathy. Bull Exp Biol Med. 2004;138(6):607-12.

Menna P, Salvatorelli E, Minotti G. Doxorubicin degradation in cardiomyocytes. J Pharmacol Exp Ther. 2007;322(1):40819.

Merten KE, Jiang Y, Feng W, et al. Calcineurin activation is not necessary for doxorubicin-induced hypertrophy in $\mathrm{H} 9 \mathrm{c} 2$ embryonic rat cardiac cells: involvement of the phosphoinositide 3-kinase-Akt pathway. J Pharmacol Exp Ther. 2006;319(2):934-40. 
Muntoni F. Cardiomyopathy in muscular dystrophies. Curr Opin Neurol. 2003;16(5):577-83.

Oliveira PJ, Wallace KB. Depletion of adenine nucleotide translocator protein in heart mitochondria from doxorubicin-treated rats-relevance for mitochondrial dysfunction. Toxicology 2006;220(2-3):160-8.

Palle J, Frost BM, Peterson C, et al. Doxorubicin pharmacokinetics is correlated to the effect of induction therapy in children with acute myeloid leukemia. Anticancer Drugs. 2006;17(4):385-92.

Park C, So HS, Shin CH, et al. Quercetin protects the hydrogen peroxide-induced apoptosis via inhibition of mitochondrial dysfunction in $\mathrm{H} 9 \mathrm{c} 2$ cardiomyoblast cells. Biochem Pharmacol. 2003;66(7):1287-95.

Perrot A, Sigusch HH, Nagele H, et al. Genetic and phenotypic analysis of dilated cardiomyopathy with conduction system disease: demand for strategies in the management of presymptomatic lamin A/C mutant carriers. Eur J Heart Fail. 2006;8(5):484-93.

Potemski P, Polakowski P, Wiktorowska-Owczarek AK, et al. Amifostine improves hemodynamic parameters in doxorubicin-pretreated rabbits. Pharmacol Rep. 2006;58(6):966-72.

Prasad S, Soldatenkov VA, Srinivasarao G, et al. Intermediate filament proteins during carcinogenesis and apoptosis (Review). Int J Oncol. 1999;14(3):563-70.

Rasola A, Bernardi P. The mitochondrial permeability transition pore and its involvement in cell death and in disease pathogenesis. Apoptosis. 2007;12(5):815-33.

Santos DL, Moreno AJ, Leino RL, et al. Carvedilol protects against doxorubicin-induced mitochondrial cardiomyopathy. Toxicol Appl Pharmacol. 2002;185(3):218-27.

Schafer ZT, Kornbluth S. The apoptosome: physiological, developmental, and pathological modes of regulation. Dev Cell. 2006;10(5):549-61.

Shimasaki H, Ueta N, Mowri HO, et al. Formation of age pigment-like fluorescent substances during peroxidation of lipids in model membranes. Biochim Biophys Acta. 1984;792(2):123-9.

Solem LE, Heller LJ, Wallace KB. Dose-dependent increase in sensitivity to calcium-induced mitochondrial dysfunction and cardiomyocyte cell injury by doxorubicin. J Mol Cell Cardiol. 1996;28(5):1023-32.

Spallarossa P, Garibaldi S, Altieri P, et al. Carvedilol prevents doxorubicin-induced free radical release and apoptosis in cardiomyocytes in vitro. J Mol Cell Cardiol. 2004;37 (4):837-46.
Takemura G, Fujiwara H. Doxorubicin-induced cardiomyopathy from the cardiotoxic mechanisms to management. Prog Cardiovasc Dis. 2007;49(5):330-52.

Taylor AL, Bulkley BH. Acute adriamycin cardiotoxicity: morphologic alterations in isolated perfused rabbit heart. Lab Invest. 1982;47(5):459-64.

Terman A, Brunk UT. Autophagy in cardiac myocyte homeostasis, aging, and pathology. Cardiovasc Res. 2005;68 (3):355-65.

Ueno M, Kakinuma Y, Yuhki K, et al. Doxorubicin induces apoptosis by activation of caspase- 3 in cultured cardiomyocytes in vitro and rat cardiac ventricles in vivo. $\mathrm{J}$ Pharmacol Sci. 2006;101(2):151-8.

Unverferth DV, Magorien RD, Unverferth BP, et al. Human myocardial morphologic and functional changes in the first 24 hours after doxorubicin administration. Cancer Treat Rep. 1981;65(11-12):1093-7.

Villani F, Galimberti M, Monti E, et al. Effect of ICRF-187 pretreatment against doxorubicin-induced delayed cardiotoxicity in the rat. Toxicol Appl Pharmacol. 1990;102 (2):292-9.

von Harsdorf R, Li PF, Dietz R. Signaling pathways in reactive oxygen species-induced cardiomyocyte apoptosis. Circulation. 1999;99(22):2934-41.

Wallace KB. Doxorubicin-induced cardiac mitochondrionopathy. Pharmacol Toxicol. 2003;93(3):105-15.

Wattanapitayakul SK, Chularojmontri L, Herunsalee A, et al. Screening of antioxidants from medicinal plants for cardioprotective effect against doxorubicin toxicity. Basic Clin Pharmacol Toxicol. 2005;96(1):80-7.

Wayman N, McDonald MC, Thompson AS, et al. 5-Aminoisoquinolinone, a potent inhibitor of poly (adenosine 5'diphosphate ribose) polymerase, reduces myocardial infarct size. Eur J Pharmacol. 2001;430(1):93-100.

Xu MF, Tang PL, Qian ZM, et al. Effects by doxorubicin on the myocardium are mediated by oxygen free radicals. Life Sci. 2001;68(8):889-901.

Yan L, Vatner DE, Kim SJ, et al. Autophagy in chronically ischemic myocardium. Proc Natl Acad Sci U S A. 2005;102(39):13807-12.

Yue TL, Wang C, Romanic AM, et al. Staurosporine-induced apoptosis in cardiomyocytes: a potential role of caspase-3. J Mol Cell Cardiol. 1998;30(3):495-507.

Zhou S, Palmeira CM, Wallace KB. Doxorubicin-induced persistent oxidative stress to cardiac myocytes. Toxicol Lett. 2001;121(3):151-7. 